\title{
Summary of: The impact of General Dental Council registration and continuing professional development on UK dental care professionals: (1) dental nurses
}

FULL PAPER DETAILS

1*-3Edinburgh Postgraduate Dental Institute, University of Edinburgh, 4th Floor, Lauriston Building, Lauriston Place, Edinburgh, EH3 9HA ${ }^{*}$ Correspondence to: Stephen Turner Email:s.turner@dundee.ac.uk

Refereed Paper

Accepted 25 May 2012

DOI: $10.1038 /$ sj.bdj.2012.664

British Dental Journal 2012; 213: E2

\author{
S. Turner, ${ }^{1}$ M. K. Ross ${ }^{2}$ and R. J. Ibbetson ${ }^{3}$
}

Objective To investigate the impact of GDC registration and mandatory CPD on dental nurses' views, job satisfaction and intention to leave. Design Postal/online survey, conducted in parallel with a survey of dental technicians. Setting UK private and NHS practices, community services, dental hospitals. Subjects and methods Representative sample of General Dental Council registrants. Main outcome measures Job satisfaction; intention to leave profession (dependent variable in regression analysis). Results Eleven were ineligible (left profession, moved abroad); 267 (44\% of those eligible) responded, all female. Respondents' mean age was 38.2 years (sd 10.74). The general principle of registration was endorsed by 67\%, and compulsory registration by 51\%, but the fee level by only 6\%. Most nurses did not feel that registration had affected their view of dental nursing as a career (56\%), their role (74\%) or status (86\%) within the dental team, or that CPD helped them to do their job better (76\%). Fiftly-six percent were not satisfied with their job, and 22\% intended to leave the profession. Intention to leave was predicted by younger age and greater dissatisfaction with physical working conditions and opportunities to progress. Conclusions Widely held criticisms regarding the costs and relevance of registration and CPD coupled with a potentially high level of attrition from the profession suggest a review of the fee and salary structure and greater financial support for CPD is warranted.

\section{EDITOR'S SUMMARY}

It was never going to be easy, or popular, and so it has proved. The mandatory registration of dental nurses was an issue that had been hotly debated for many years before becoming a reality in the summer of 2008.

The concept of the dental team requires a professional approach from all members if it is to have any real meaning at all. Parallels with medical practice are of course always to hand and the public expectation that those treating and caring for their health should be properly trained, regulated and subject to continuing education is not surprising. Similarly unsurprising is that the central problem identified from dental nurses in this research was the cost of registration.

However, it is also the cost in time and money of continuing professional development (CPD) that causes grievances as well as the lingering overall concern that as a group dental nurses are still not properly regarded as being professionals. In fairness, it has to be said that these are still very early days. It would have been so instructive to have been able to have referred to similar research undertaken in 1925, just four years after similar registration was implemented for dentists, even though it took another seventy plus years to attach CPD as a further condition. One suspects that similar disgruntlements might have been voiced then.

Perhaps the central point that we should take from this valuable study concerns the way in which we in the dental team treat and regard our dental nurse colleagues both amongst ourselves and also publicly. Self-respect grows from mutual respect and the values of professionalism and life-long learning will take many more years to become as commonplace and accepted as for other longer-term, existing professional groups.

All this notwithstanding, addressing the issue of the registration costs for arguably the least well paid members of the team should be rekindled as an important priority. It is one that would be demonstrative of the type of professional solidarity which it would be laudable for the rest of the team to support.

The full paper can be accessed from the $B D J$ website (www.bdj.co.uk), under 'Research' in the table of contents for Volume 213 issue 2.

Stephen Hancocks Editor-in-Chief

DOI: 10.1038/sj.bdj.2012.643 
TO ACCESS THE BDJ WEBSITE TO READ THE FULL PAPER:

- BDA Members should go to www.bda.org.

- Click the 'login' button on the right-hand side and enter your BDA login details.

- Once you have logged in click the 'BDJ' tab to transfer to the BDJ website with full access.

IF YOUR LOGIN DETAILS DO NOT WORK:

- Get a password reminder: go to www.bda.org, click the login button on the right-hand side and then click the forgotten password link.

- Use a recommended browser: we recommend Microsoft Internet Explorer or Mozilla Firefox.

- Ensure that the security settings on your browser are set to recommended levels.

IF YOU HAVE NOT YET SIGNED UP TO USE THE BDA WEBSITE:

- Go to www.bda.org/getstarted for information on how to start using the BDA website.
IN BRIEF

- Investigates views of dental nurses on GDC registration.

- Reflects the common feeling among dental nurses that registration and CPD have increased financial pressures.

- Informs the ongoing debate on the organisation and delivery of CPD for the whole dental team.

- May assist in efforts to increase the job satisfaction of dental nurses.

\section{COMMENTARY}

Since 2008, dental care professionals (DCPs) are required to register with the GDC and complete a minimum number of verifiable and non-verifiable CPD hours over a five-year cycle in order to maintain registration. In this study of 267 dental nurses, approximately two thirds of the dental nurses endorsed the general principle of registration. However, only just over a half of those who responded to the postal questionnaire endorsed the principle of compulsory registration.

There was a strong negative feeling on the cost of registration, with only $6 \%$ endorsing the current fee level and $88 \%$ of all negative comments regarding registration being related to costs. A comparison was drawn between the cost of registration for general medical nurses, which is considerably lower than dental nurses. Consideration could be given to the cost of registration for dental nurses and perhaps a fee structure that incorporates allowances for dental nurses working on a part time basis could be put into place.

A large majority of dental nurses that responded felt that the $\mathrm{CPD}$ they had carried out had not affected their role or status within the team or enabled them to do their job better. Perhaps disturbingly, 22\% of those questioned intended to leave the profession. Rather than being related to costs of CPD or registration, intention to leave the profession appeared to be related to age, greater dissatisfaction with physical working conditions and opportunities to progress.
In our opinion, this study demonstrates the importance of creating a supportive environment for dental nurses within the team and the need to recognise and appreciate the professional status of this DCP group. Helping dental nurses to access CPD and select the most appropriate form of CPD to enhance their professional development and allowing them to use their skill set may lead to greater job satisfaction and higher standards of patient care. The authors rightly point out that dental nurses are an invaluable asset to the dental team in the role of providing high quality patient care.

\section{Nicola Gough BSc RDH} and Sue Bagnall BSc RDH Directors, cpd4dentalnurses.co.uk and cpd4dentalhygienists.co.uk

\section{AUTHOR QUESTIONS AND ANSWERS}

1. Why did you undertake this research? We were very aware that despite some controversy surrounding the 2006 changes to GDC regulations which made dental nurse registration and CPD mandatory, no independent representative studies of the experiences and views of dental nurses had been published in the following five years. As dental nurses are the largest single group of GDC registrants, we thought it important to follow up concerns that were expressed at the time of the 2006 changes that dental nurses might consider leaving the profession as a result. Nurses' reports of the views of dentists they work with may also reflect on how well the dental team as a whole are responding to the new arrangements.

2. What would you like to do next in this area to follow on from this work?

We have an opportunity to follow up this study (and parallel surveys of dental hygienists, hygienist-therapists, and technicians), by examining the actual pattern of attrition from these professions. We are also hoping to obtain funding for a more in-depth view of dental teams by interviewing dentists, hygienists, hygienist-therapists and nurses and patients in selected areas of employment. 